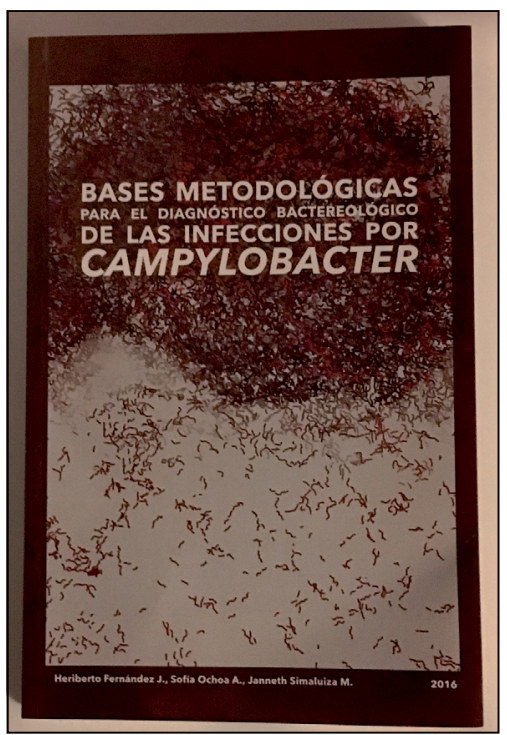

\section{Bases Metodológicas \\ para el Diagnóstico \\ Bacteriológico de las \\ Infecciones por Campylobacter}

\section{Autores: \\ Heriberto Fernández \\ Sofia Ochoa \\ Janneth Simaluiza}

Editorial Copygraph Ltda.

Santiago de Chile.

$\mathrm{N}^{\circ}$ de páginas: 113 .

ISBN 978-956-7119-79-0

\section{Presentación}

Presentar un libro, siempre es un acto importante. También un honor que me hace este compañero de tantas luchas y sueños en la ciencia y la poesía.

Primero, porque anunciamos a la comunidad científica y profesional el nacimiento de un libro que recoge parte del conocimiento, en un área de la ciencia. Cuando un profesor, nos comunica eso, a través de la experiencia reunida en su desarrollo profesional, al traspasar su saber, está haciendo un generoso acto de amor al transmitir este saber acumulado.

Segundo, presentar un libro de un dilecto ex alumno y luego por muchos años mi colega de trabajo en el fascinante mundo de la microbiología, es una tarea difícil y a la vez grata. Difícil porque más allá de los afectos y la amistad tengo el deber de ser objetivo.

Sin temor a equivocarme, el Dr. Heriberto Fernández es un maestro de la microbiología y se ha ganado el afecto de sus alumnos y colegas y de la comunidad internacional. Es un maestro, porque muestra caminos y eso lo repite en su libro, con sus co-autores Sofía Ochoa y Janneth Simaluiza, y porque al tener un camino propio, fue más allá de los que sus profesores le mostraron.

El Dr. Fernández es tecnólogo médico, formado en la Universidad Austral de Chile y Magister y Doctor en Ciencias de la Universidade Federal de Sao Paulo. Ha publicado numerosos trabajos de su especialidad y ha dictado una gran cantidad de cursos en América Latina ha sido conferencista en congresos en América, Europa, Asia y Australia.

Desde los primeros años de su carrera académica, sus investigaciones se relacionaron con el diagnóstico de bacterias de carácter zoonótico y desde 1980, su interés se centró en especies de la actual Familia Campylobacteraceae, formada por los géneros Campylobacter y Arcobacter, y las relaciones epidemiológicas de estas bacterias entre el ser humano, los animales, el medio ambiente y la producción de alimentos, alcanzando reconocimiento internacional por su trabajo sistemático en este grupo bacteriano.

Campylobacter fue descrito microscópicamente en muestras fecales de pacientes con diarrea en el año 1886, pero fue sólo en la década de 1970 que especies del género Campylobacter, particularmente $C$.jejuni y $C$. coli, surgen como agentes emergentes de infecciones entéricas en el ser humano.

La Organización Mundial de la Salud los considera como los primeros agentes de diarrea en los países industrializados y los segundos o terceros en aquellos en vías de desarrollo, indicando que la verdadera incidencia de la gastroenteritis por Campylobacter y sus secuelas son poco conocidas en países de bajos ingresos. Sin embargo, la revisión de la literatura biomédica latinoamericana permite inferir que en esta región, varias especies de Campylobacter son importantes agentes de diferentes cuadros infecciosos, con una amplia diseminación en la naturaleza, en alimentos y en una extensa gama de reservorios animales, constituyendo un problema de salud pública subestimado, porque en muchos de estos países no ha sido implementada su vigilancia epidemiológica.

Como una manera de mejorar la resolución diagnóstica de las infecciones entéricas y avanzar en el conocimiento de estas bacterias y muy conscientes de su responsabilidad social de contribuir para que la universidad siga siendo un agente evolutivo de la condición humana y atentos a sus necesidades, en un esfuerzo conjunto, académicos de la Universidad Austral de Chile y de la Universidad Técnica Particular de Loja, Ecuador, donde también el Dr. Fernández es profesor, ofrecen este libro sobre las bases metodológicas para el diagnóstico bacteriológico de las infecciones por Campylobacter. Con ello se pretende contribuir a complementar las capacidades resolutivas del capital humano involucrado en el diagnóstico de laboratorio de la diarrea, en los problemas epidemiológicos y en los de inocuidad alimentaria asociados a este grupo bacteriano.

Sin embargo, en nuestros hospitales, aun sabiendo de la frecuencia de Campylobacter en cuadros diarreicos y otros, no se tiene implementado su diagnóstico.

\section{Vamos al libro}

Está estructurado desde una visión histórica, siguiendo por las características generales de su morfología $\mathrm{y}$ métodos de aislamientos, que los autores conocen y exponen, para que los interesados puedan desarrollar las técnicas de aislamiento con certeza. Luego, siguen las presentaciones clínicas y lo fundamental, el diagnóstico 
de laboratorio de Campylobacter, donde se recalca el examen microscópico directo de las muestras, los medios selectivos para un aislamiento exitoso y las condiciones de cultivo, para rematar en la identificación presuntiva y de certeza de estos microrganismos. Hay un capítulo de susceptibilidad in vitro a los antimicrobianos y la vigilancia epidemiológica de la resistencia.

Los autores, Heriberto Fernández, Sofía Ochoa y Janneth Simaluiza, en una secuencia lógica, incorporan un capítulo sobre identificación y tipificación por métodos moleculares.

Los anexos son muy importantes porque enseñan a conservar las cepas de Campylobacter, cómo preparar los medios de transporte de las muestras, de cultivo para su aislamiento e identificación, como también de medios cromogénicos selectivos e indicadores. O sea, muestran los secretos de laboratorio que a veces no se cuentan.

Agregan los autores un capítulo de modelos o protocolos diagnósticos en alimentos y agua, como también protocolos de identificación molecular de estas bacterias. Las referencias bibliográficas son pertinentes, inclusive con publicaciones de los años 2015 y 2016.

Es pues, un agrado poner en el conocimiento de la comunidad científica y profesional, un libro concreto, con las técnicas del día a día en el estudio de Campylobacter. Esperemos que el esfuerzo de los autores se vea recompensado con la instalación del diagnóstico de Campylobacter en los diversos hospitales de las regiones del país y en general en toda América Latina.

Debemos agradecer el esfuerzo de los autores Heriberto Fernández, Sofía Ochoa y Janneth Simaluiza, que esperan de los profesionales y de los estudiantes una respuesta proactiva en el estudio de estos microorganismos.

Luis Zaror

Profesor Titular de Microbiología Clínica Universidad Mayor, sede Temuco ex profesor en la Universidad Austral de Chile.

\section{Prólogo}

Constituye un honor que el primer autor de esta importante obra, brillante académico y amigo, con quién me ha correspondido transitar durante muchos años por la vida universitaria, tecnólogo médico Dr. Heriberto Fernández Jaramillo, me hubiese solicitado escribir algunas palabras, a modo de prólogo de este texto.

El Dr. Fernández Jaramillo ha destacado como líder de opinión en el ámbito de la Microbiología, tanto en Chile como fuera de nuestro país, especialmente en Campylobacter, tema central de esta obra. Formador de numeroso personal de salud, médicos, enfermeras, tecnólogos médicos por nombrar algunas profesiones, en el ámbito del pregrado y del post grado, adquiere el mérito con este libro de seguir formando a sus estudiantes y contribuir a la documentación de quienes fueron sus profesores. El primer autor, destacado investigador y con numerosas publicaciones de calidad en el tema y de alto impacto en la comunidad científica, logra, además, con sus características personales y su capacidad de convocar, reunir en torno a él a dos excelentes académicas: Sofía Ochoa y Janneth Simaluiza, que complementan la calidad del texto.

El presente libro es la obra más completa que he tenido en mis manos, en los tópicos que ella analiza. Constituye una didáctica y detallada revisión de las características generales de Campylobacter, sus diferentes especies, su epidemiología, fisiopatogenia y presentaciones clínicas, culminando con una detallada y muy completa descripción de todos sus aspectos de laboratorio que permiten un diagnóstico exacto y las características específicas de la especie de Campylobacter que se está aislando.

Los autores demuestran su experiencia al ordenar esta obra en capítulos correlativos muy completos e integrados entre ellos, en un lenguaje, presentación y narrativa que, aun siendo un texto científico, logra ser ameno y fácil de seguir. Es destacable la calidad de sus figuras, notables en sus detalles y nitidez.

Tengo la certeza que esta obra tendrá una gran influencia en la formación de estudiantes de pregrado y post grado, de enorme interés para los profesionales de salud, en particular médicos, tecnólogos médicos, epidemiólogos, médicos veterinarios y laboratoristas. Todos los conocimientos que los lectores de este magnífico libro adquieran, les permitirá mejorar sus potencialidades y competencias en este tema, logrando el objetivo final de nuestro quehacer, prevenir la enfermedad y mejorar la salud de nuestra población.

No tengo duda que si Theodor Escherich, quién entregó las primeras observaciones de bacterias semejantes a Campylobacter en 1886, pudiera leer este texto, estaría orgulloso del avance que ha logrado el conocimiento humano en Campylobacter y gratamente sorprendido de la calidad pedagógica que los autores entregan en este libro.

Mis sinceras felicitaciones al Dr. Fernández Jaramillo y a las colegas que integran este equipo de autores, quienes ofrecen al mundo científico una magnífica obra.

Mario Calvo

Profesor Titular

Prorrector Universidad Austral de Chile 